\title{
Programas de Intervenção de Escritas Inventadas: Comparação de uma Abordagem Transmissiva e Construtivista
}

\author{
Invented Spelling Training Programs: Comparing Knowledge-Transmission Model \\ and the Constructivist Model of Learning
}

\author{
Cristina Silva*, $a$ \& Tiago Almeida ${ }^{b}$ \\ ${ }^{a}$ ISPA - Instituto Universitário de Ciências Psicológicas, Sociais e da Vida, Lisboa, Portugal \\ \& ${ }^{b}$ Instituto Politécnico de Lisboa, Escola Superior de Educação de Lisboa, Lisboa, Portugal
}

\begin{abstract}
Resumo
O objectivo deste estudo é comparar programas de intervenção de escritas inventadas de natureza construtivista ou transmissiva. Participaram nesta investigação 78 crianças de idade pré-escolar, cujas escritas não representavam ainda os sons, tendo sido distribuídas por cinco grupos, quatro experimentais e um de controlo, equivalentes quanto à idade, inteligência, número de letras conhecidas e consciência fonológica. Entre o pré e o pós teste, as crianças dos grupos experimentais participaram num programa de intervenção de escritas inventadas de natureza construtivista ou transmissiva, manipulando-se ainda variáveis relacionadas com as características das palavras de treino e o tipo de instruções. Só se verificou uma evolução significativa da qualidade das escritas inventadas nas crianças que participaram nos programas de intervenção de natureza construtivista.

Palavras-chave: Programas de Intervenção em Escritas Inventadas, construtivismo, instrução transmissiva.
\end{abstract}

\begin{abstract}
The aim of this study was to compare two intervention programs of invented spelling, a constructivist and a knowledge-transmission one. Participants were 78 pre-school children, whose invented spelling did not represent any sounds, distributed into five groups, four experimental and a control one with equivalent age, intelligence, number of known letters and phonological awareness. Between the pre-and post-test, children from experimental groups participated in an intervention program of invented spelling (constructivist or knowledge transmission), and there were manipulated variables related to the characteristics of the training words and the type of instructions. There has been significant evolution in the quality of invented spelling only in children who participated in the constructivist intervention programs.

Keywords: Invented Spelling Programs, constructivism, knowledge-transmission.
\end{abstract}

Existe uma oposição histórica entre os modelos transmissivos de aprendizagem e o modelo construtivista de aquisição de conhecimentos. O modelo de instrução baseado na perspetiva transmissiva enfatiza a memorização, a exercitação e a prática, necessárias para que haja interiorização dos conhecimentos na memória a longo prazo. Vários autores (Kirschner, Sweller, \& Clark, 2006) defendem que a instrução direta e explícita é aquela que providencia, com maior eficácia, as informações que clarificam e explicitam os conceitos e procedimentos que os alunos precisam de aprender. Ainda de acordo com estes autores (Kirschner et al., 2006) a instrução direta e explícita promove maior compreensão e apropriação dos

\footnotetext{
"Endereço para correspondência: Instituto Universitário de Ciências Psicológicas, Sociais e da Vida, Rua Jardim do Tabaco, 34, Lisboa, Portugal 1149 041. E-mail: csilva@ispa.pt e tiagoa@eselx.ipl.pt
}

conhecimentos por ser mais compatível com a arquitetura cognitiva humana, nomeadamente no que respeita às relações entre a memória a curto prazo e a memória de trabalho. Assim, a única instrução capaz de promover alterações são as explícitas e diretas, assentes na consolidação e sistematização das instruções através de exercícios de repetição (Clark, 2009; Sweller, Kirschner, \& Clark, 2007). Para Sweller (2010) as perspetivas construtivistas de ensino não têm em consideração as limitações da memória de trabalho, considerando que as instruções usadas são assentes em perguntas orientadas que provocam uma imensa sobrecarga na memória de trabalho (Sweller, 2012). Para que tal não aconteça, as instruções devem transmitir uma demonstração explícita e exata de como (decisões e ações) e quando (condições) se deve proceder para resolver um problema ou concluir uma tarefa, assim como providenciar um conjunto de exercícios diversificados e uma explicitação do conhecimento declarativo que permita 
às crianças adaptar um procedimento a novas situações. Além disso, essas instruções devem vir acompanhadas de um feedback corretivo (Clark, 2009).

As teorias construtivistas, por seu lado, defendem que os indivíduos constroem os seus próprios conhecimentos com base na interação entre conhecimentos prévios e os novos conhecimentos que estão a apreender. Assim, aprender não depende de processos passivos em que o sujeito se limita a receber de um agente mais competente informações, mas de processos ativos de construção de conhecimentos. A operacionalização pedagógica do modelo construtivista assenta em atividades de questionamento e argumentação no quadro de interações sociais (Kuhn, 2005 , 2007). Este modelo vai permitir aumentar a interação entre o conhecimento disponível (já adquirido) e o novo (a ser aprendido) através das autoexplicações feitas durante os períodos de discussão que estimulam a integração de nova informação na base do conhecimento já existente e armazenado na memória a longo prazo (Schmidt, Loyens, van Gog, \& Paas, 2006).

A abordagem construtivista tem sido aplicada ao estudo das escritas pré-convencionais das crianças de idade pré-escolar. Nesta linha teórica, as tentativas de escrita das crianças (escrita inventada) são consideradas, em certa medida, uma atividade de resolução de problemas, envolvendo procedimentos analíticos que permitam uma gradual representação das relações entre segmentos orais e escritos. Não se trata de um processo de memorização e de restituição de escritas convencionais, mas sim de um processo de experimentação por parte das crianças que, apesar de não saberem ler, usam os conhecimentos que adquiriram sobre a natureza das escritas para representar na escrita os sons que identificaram nas palavras. Nessa medida, os procedimentos de escrita inventada implicam um envolvimento ativo das crianças (Alves Martins, \& Silva, 2006).

Para Ferreiro (1988, 2002), a autora mais representativa desta orientação, os mecanismos fundamentais para a evolução da escrita infantis são as descobertas que as crianças fazem (e os conflitos cognitivos desencadeados por essas descobertas) no decurso das suas tentativas de escrita. As suas investigações pioneiras (Ferreiro, 1988; Ferreiro \& Teberosky, 1986) mostraram que as conceptualizações das crianças sobre a linguagem escrita evoluem ao longo de três níveis essenciais.

Numa fase inicial, as crianças começam por diferenciar o desenho da escrita e por elaborar critérios que tornam uma série de letras passíveis de transmitir uma mensagem. Estes critérios são uma quantidade mínima de letras e a não utilização de uma mesma sequência de letras em diferentes palavras. Posteriormente, dá-se um refinamento nos processos de diferenciação qualitativo e quantitativo entre os encadeamentos de letras, de modo a assegurar diferenças na representação de diferentes palavras; nesta fase as crianças não fazem ainda qualquer correspondência entre a linguagem oral e escrita (escritas pré-silábicas) e as letras usadas são aleatórias. As tentativas de coordenar a linguagem escrita com a linguagem oral iniciam-se, frequentemente, com a hipótese silábica com base na qual as crianças escrevem uma marca gráfica por sílaba. Neste momento evolutivo, as crianças começam não só a ter a noção de que as palavras orais são constituídas por vários componentes sonoros, mas passam sobretudo a ter em conta que a cada um desses componentes corresponde uma letra específica a qual representa as propriedades sonoras desse segmento. Através deste tipo de relação as crianças resolvem o problema da correspondência entre a totalidade da palavra e os seus elementos constituintes. Esta perceção estará, provavelmente, na base da descoberta de que sons idênticos terão de ser representados pela mesma letra e sons diferentes terão de ser notados através de letras diferentes. Gradualmente, as crianças passam a efetuar uma análise que ultrapassa o nível da sílaba, ainda que não procedam a uma representação de todos os fonemas das palavras. Este percurso termina com a escrita alfabética em que as crianças passam a realizar uma análise fonémica das palavras e a selecionar as letras adequadas para a representação de todos os fonemas. A partir deste nível, a progressão infantil passa a estar relacionada com o domínio da ortografia do sistema.

Um outro paradigma de estudo das escritas infantis prévias ao ensino formal, designado de fonológico, baseia-se no pressuposto de que a principal tarefa da criança, ao aprender a ler e escrever, consiste em apreender que as letras representam sons na pronúncia das palavras. Do ponto de vista da abordagem fonológica (Ehri, 1998), à medida que as crianças aprendem os nomes e os sons das letras, elas começam a compreender que as letras representam sons estáveis na pronúncia das palavras e começam a evidenciar essa compreensão nas suas escritas inventadas. Nesta linha, a aprendizagem das letras serve de base para as primeiras correspondências grafo-fonéticas convencionais. No entanto, esta perspetiva não explicita quais os mecanismos de aprendizagem que estão na base da apropriação das relações letras/sons.

Dentro desta linha, Cardoso-Martins e Batista (2005) sugeriram que a escrita silábica definida por Ferreiro (1988) resultaria da tentativa da criança de escrever as letras cujo som ela é capaz de detetar na pronúncia das palavras, evidenciando que as letras nas escritas silábicas das crianças correspondiam, em geral, às vogais ou então às consoantes cujo nome podia ser identificado na pronúncia da palavra (por exemplo, o nome das letras $Z$ e $A$ na escrita $Z A$ para a palavra zebra). Assim, os conhecimentos adquiridos ou ensinados sobre o nome das letras ajudariam as crianças a detetar os nomes das letras na pronúncia de algumas palavras (Treiman, 1994) refletindo-se nos processos de fonetização, ou seja, na forma como as crianças são capazes de mobilizar as letras convencionais na representação dos sons que identificam na linguagem oral. Este efeito facilitador do nome das letras não é geralmente considerado na perspetiva de Ferreiro. No entanto, tanto na perspetiva de Ehri (1998), como de Ferreiro (1988), as escritas mais evoluídas são aquelas em que as crianças 
Silva, C. \& Almeida, T. (2015). Programas de Intervenção de Escritas Inventadas: Comparação de uma Abordagem Transmissiva e Construtivista.

começam a mobilizar mais letras corretas para representar os sons das palavras.

Independentemente da abordagem teórica que se considere, é hoje consensual que a escrita inventada das crianças de idade pré-escolar constitui uma atividade que leva à descoberta do princípio alfabético, permitindo a compreensão da relação entre a oralidade e a escrita (e.g. Alves Martins, \& Silva, 2006; Ouellette \& Sénéchal, 2008; Silva \& Alves Martins, 2002; Treiman, 1994, 2006). Estes autores consideram que as atividades de escrita inventada são um instrumento importante de ajuda à compreensão do princípio alfabético, na medida em que, quando tentam escrever, as crianças são levadas a pensar na linguagem oral e nos sons que a constituem, na linguagem escrita, e nas letras que a compõem e nas relações entre ambas.

Baseado no paradigma de instrução construtivista, Alves Martins e Silva, (2006, 2009), elaboraram um modelo de treino que utiliza o conflito sociocognitivo como fator de evolução das escritas inventadas. Nestes estudos, os autores (Alves Martins \& Silva, 2006, 2009) trabalharam com crianças de idade pré-escolar que ainda não relacionavam o escrito com segmentos do oral (escritos pré-silábicos), e consequentemente usavam letras de forma aleatória, submetendo-as a uma metodologia de treino inspirada em referenciais teóricos sócio-construtivistas. Durante sessões individuais, era pedido às crianças para escreverem um conjunto de palavras e para confrontarem as suas escritas com as de outra criança hipotética da mesma idade com conceptualizações sobre a linguagem escrita um pouco mais avançadas (silábicas ou alfabéticas consoante os estudos). Neste tipo de intervenção era solicitado às crianças para analisar as palavras a escrever nos seus componentes orais e ver as letras mais adequadas, para pensarem sobre os dois escritos, escolherem o mais bem escrito e para justificarem a sua escolha. As principais atividades cognitivas eram prever o número e quais as letras a escrever, comparar o seu escrito com o outro mais evoluído, avaliar qual seria a melhor e justificar a sua escolha. Esta abordagem é claramente construtivista na medida em que é baseada nas descobertas que as crianças fazem. Eram utilizadas nas sessões iniciais palavras facilitadoras, ou seja, palavras cujo som da primeira sílaba coincidia com o nome de uma letra, ou seja, palavras que permitiam que as crianças mobilizassem mais facilmente a letra associada ao som.

Estes programas de treinos permitiram que as crianças aumentassem o número de fonetizações no pós-teste, passando a utilizar muito mais letras convencionais para representar as palavras que lhes eram pedidas para escrever e chegando em algumas palavras à escrita alfabética; também generalizaram as correspondências grafo-fonológicas que foram trabalhadas durante os programas para novas correspondências nunca trabalhadas, mostrando assim que foram capazes de perceber e de mobilizar a lógica subjacente ao princípio alfabético.
Treiman (1994), mostrou que a probabilidade das crianças de idade pré-escolar mobilizarem corretamente a primeira consoante é maior quando escrevem palavras em que a sílaba inicial coincide com um nome da letra que a criança conhece. Assim, é mais provável que a criança escreva a letra "p" na palavra "pêssego" do que na palavra "pano". A análise de um efeito facilitador similar para palavras cuja sílaba inicial coincide com o som da letra (eg. escrever o p na palavra peru), não tem sido tão explorado, provavelmente por se saber que existe maior dificuldade por parte das crianças em aprender os sons das letras do que os seus nomes. Isto acontece porque os sons das letras correspondem a fonemas, os quais são mais difíceis de discriminar e de articular e não possuem a forma acústica de um item lexical que é natural para as crianças como o nome das letras. Por outro lado, as referências às letras nos contextos sociais baseiam-se nos nomes e não nos sons das letras. Apesar disso, alguns dados (Levin, Shatil-Carmon, \& Asif-Rave, 2006) sugerem que as crianças obtêm ganhos equivalentes quando lhes são ensinadas o nome ou o som da letra, no que respeita à sua capacidade para reconhecer palavras. Os mesmos autores demonstraram que a abstração do som da letra não decorre diretamente do nome da letra, tendo aquele de ser ensinado de forma explícita. Para especificar o papel destas variáveis, Silva, Almeida e Alves Martins (2010), usando o paradigma construtivista de Alves Martins e Silva (2006), analisaram o papel do nome e som das letras, quer ao nível das características facilitadoras das palavras, quer ao nível das instruções dadas. Assim, os autores manipularam as características de algumas palavras usadas nos programas de escrita (palavras cuja sílaba inicial coincidia com o nome da letra vs. palavras cuja sílaba inicial coincidia com o som das letras) e a natureza das instruções (instruções com indicações para as crianças pensarem no nome das letras $v s$. instruções com indicações para as crianças pensarem no som das letras), formando assim quatro grupos experimentais (em função do cruzamento das várias variáveis) com crianças em idade pré-escolar, cujas escritas eram pré-silábicas. As crianças dos vários grupos aumentaram o número de fonetizações correta em igual proporção, passando a utilizar muito mais letras convencionais para representar as palavras que lhes eram pedidas. Estes resultados sugerem que todas as condições experimentais favoreceram o aumento de mobilização de letras corretas e melhoraram a qualidade das escritas inventadas. No entanto, no grupo em que as palavras facilitadoras tinham sílabas que coincidiam com o som das letras e onde as crianças eram induzidas a refletir sobre os sons das letras, o número de consoantes fonetizadas corretas era superior quando comparada com os restantes grupos.

Os vários estudos acima descritos (Alves Martins \& Silva, 2006, 2009; Silva et al., 2010), e os respetivos programas de intervenção ao nível das escritas pré-convencionais têm implícito a superioridade dos princípios construtivistas de instrução para a evolução infantil na qualidade dos seus 
escritos. Contudo, não existe nenhum estudo que confirme que uma abordagem mais próxima dos pressupostos do modelo transmissivo teria piores resultados. Assim, apesar dos progressos nas escritas inventadas evidenciados após a aplicação de programas de treino baseados na metodologia construtivista usada por Alves Martins e Silva (2006), existe a necessidade de comparar a eficácia desta metodologia com outra desenhada de acordo com os princípios do modelo transmissivo com instruções mais explicitas, no sentido de clarificar quais as condições que melhor ajudam as crianças de idade pré-escolar a evoluir nas suas escritas. Sobretudo, porque, segundo os teóricos desta linha, as instruções diretas e explicitas correspondem a menor sobrecarga na memória de trabalho e as crianças desta idade apresentam claras limitações a este nível. Para se atingir este objetivo, pretendemos replicar duas das condições do estudo de Silva et al. (2010), - nomeadamente uma condição em que as palavras facilitadoras incluem palavras cuja sílaba inicial coincidia com o nome da letra e instruções centradas no nome da letra e outra em que em que as palavras facilitadoras incluem palavras cuja sílaba inicial coincidia com o som das letras e instruções centradas no som da letra -, desenhando programas de treino de acordo com uma abordagem de instrução construtivista ou uma abordagem baseada no modelo transmissivo.

Assim colocámos como questões de investigação para este estudo:

1. Será que a utilização da instrução construtivista e da instrução transmissiva nos programas de intervenção de escritas inventadas terá um impacto diferente na evolução das conceptualizações infantis?

2. Será que a utilização da instrução construtivista e da instrução transmissiva nos programas de intervenção terá um impacto diferente no número total de letras corretamente fonetizadas?

\section{Método}

\section{Desenho Experimental}

Trata-se dum estudo experimental com intervenção em que os participantes realizaram um pré teste e um pós teste com o objetivo de avaliar o nível conceptual das escritas inventadas e o número total de fonetizações (número de letras corretamente mobilizadas). As provas realizadas no pré e pós teste foram as mesmas. As crianças foram distribuídas por cinco grupos, quatro experimentais e um de controlo de acordo com critérios de pareamento. Entre o pré e o pós testes as crianças dos grupos experimentais participaram num programa de intervenção de escritas inventadas e as crianças do grupo de controlo realizaram desenhos. Os programas dos grupos experimentais e de controlo começaram uma semana após o pré-teste e duraram cinco semanas, num total de seis sessões. O pós-teste foi realizado uma semana após o fim dos programas de intervenção. Os dois programas de intervenção ocorreram ao mesmo tempo entre Abril e Junho. É ainda de referir que os programas foram implementados por quatro ex- perimentadores treinados para o efeito e que não tinham conhecimento das hipóteses de estudo, tratando-se assim de um estudo duplo cego. Os experimentadores trabalharam em todos os grupos experimentais.

\section{Participantes}

Para selecionar os participantes foram avaliadas 161 crianças de idade pré-escolar de três jardins de infância privados. As crianças pertenciam a cinco salas de educação pré-escolar, todas com uma educadora diferente. As únicas atividades regulares relacionadas com leitura e escrita eram a leitura de histórias e atividades em que as crianças tinham de escrever o seu nome. Em Portugal o ensino da escrita e da leitura só se inicia no primeiro ano do primeiro ciclo. Todas as crianças tinham o Português como primeira língua.

Nesta fase foram avaliados os conhecimentos das crianças sobre o nome e o som das letras. A escrita das crianças foi avaliada, solicitando que escrevessem 8 palavras e uma frase. Só foram selecionadas para participar no estudo as crianças com escritas pré-silábicas em que as letras eram claramente escolhidas de forma aleatória.

Dos 161 participantes iniciais foram selecionados 78 crianças entre os 5 e os 6 anos de idade, cujos escritos eram então pré-silábicos. Todas as crianças selecionadas conheciam as cinco vogais (A, E, I, O, U) e as consoantes $\mathrm{B}, \mathrm{C}, \mathrm{D}, \mathrm{M}, \mathrm{N}, \mathrm{P}, \mathrm{R}$ e T. Estas consoantes eram necessárias para escrever as palavras do pré e pós teste.

As crianças foram distribuídas por cada um dos 4 grupos experimentais e de controlo em igual proporção quanto à turma de origem, sendo também equivalentes quanto à idade, ao nível intelectual, ao número de letras que conheciam e identificavam, e à pontuação nas provas de consciência fonológica (análise silábica e análise fonética). Esta distribuição foi realizada por pareamento.

\section{Medidas}

Conhecimento das Letras. Para determinar quantas e quais as letras que as crianças conheciam foram apresentados um conjunto de cartões com as letras do alfabeto em maiúsculas (excluindo-se $\mathrm{K}, \mathrm{W}$ e $\mathrm{Y}$ que são raras em português) e as crianças eram convidadas a nomear o nome de cada letra e o respetivo som. A pontuação possível deste teste ia de 0 a 23 .

Desempenho Cognitivo. O desempenho cognitivo foi avaliado através das matrizes progressivas coloridas de Raven (Raven, Court, \& Raven 2001) por se tratar duma prova pouco dependente dos aspetos verbais. Foi atribuído um ponto por cada resposta correta, fazendo a pontuação variar entre 0 e 36 pontos.

Consciência Fonológica. Para avaliar o nível da consciência fonológica foram aplicados duas provas da bateria de testes fonológicos de Silva (2003): a análise silábica e análise fonémica.

$\mathrm{Na}$ prova de análise silábica as crianças tinham de pronunciar de forma isolada cada uma das sílabas das palavras que eram apresentadas em desenhos. A prova era 
Silva, C. \& Almeida, T. (2015). Programas de Intervenção de Escritas Inventadas: Comparação de uma Abordagem Transmissiva e Construtivista.

constituída por 14 itens, precedidos por dois de exemplo e treino onde era realizada a segmentação silábica. A classificação na prova poderia ser entre 0 e 14 pontos.

$\mathrm{Na}$ prova de análise fonémica as crianças tinham de pronunciar de forma isolada cada um dos fones das palavras que eram apresentadas em desenhos. A prova era constituída por 14 itens, precedidos por dois de exemplo e treino onde era realizada a segmentação fonética. A classificação na prova poderia ser entre 0 e 14 pontos.
Escritas Inventadas no Pré e Pós-Teste. Para avaliar os progressos resultantes dos programas de escrita foi efetuada uma prova de ditado, que serviu como instrumento de pré e pós-teste. Nesta prova, as crianças tinham de escrever, como soubessem, um conjunto de palavras. Nenhuma destas palavras foram usadas no programa. Foram ditadas 40 palavras em duas sessões em dias consecutivos ( 20 em cada sessão). As palavras ditadas foram as que se apresentam na Tabela 1.

Tabela 1

Palavras Ditadas no Pré e Pós-Teste

\begin{tabular}{cccccccccc}
\hline BABA & PAGO & DADO & TABU & RATO & VACA & MATA & FADA & NADO & RABO \\
BICO & PIPA & DIGO & TITO & RICO & VIDA & MITO & FITA & NICO & RICA \\
BOTA & PODA & DOTA & TOTA & RODO & VOTO & MODA & FOCA & NOTA & RODA \\
BUDA & PUTO & DUDA & TUBO & RUGA & VUDU & MUDO & FUMO & NUCA & RUMO \\
\hline
\end{tabular}

Na classificação dos escritos infantis teve-se em linha de conta o nível conceptual das escritas infantis. Foram também contabilizadas o número de letras corretas utilizadas, ou seja, o número de fonetizações adequadas, quer quanto ao número total (entre 0 e 160), quer quanto ao número de consoantes iniciais (entre 0 e 40 ) e quer quanto ao número de vogais da primeira sílaba (entre $0 \mathrm{e}$ 40), sendo atribuído um ponto a cada letra corretamente mobilizada. Para as conceptualizações usámos uma grelha construída a partir dos critérios definidos por Ferreiro (1988). As categorias utilizadas foram as seguintes: escritas pré-silábicas, escritas silábicas sem fonetização, escritas silábicas com fonetização, escritas silábico-alfabéticas e escritas alfabéticas.

\section{Programas de Intervenção}

Foram desenhados dois tipos de programas de intervenção no sentido de melhorar a qualidade das escritas inventadas. Um com uma instrução transmissiva e outro com uma instrução construtivista. Em cada um destes programas manipulámos variáveis relacionadas com palavras facilitadoras e o tipo de orientação a dar à análise das palavras.

Programa de Instrução Transmissiva. Os grupos experimentais 1 e 2 tiveram, ao longo do programa de intervenção, uma instrução transmissiva. A instrução transmissiva caracterizava-se por ser diretiva e explicita no procedimento necessário para as crianças escreverem corretamente as palavras de acordo com critérios silábicos. No programa de intervenção com instrução transmissiva o procedimento seguido foi:

1. Era pedido à criança para escrever uma palavra da melhor forma que conseguisse;

2. Pedia-se à criança que lesse a palavra que tinha escrito e que acompanhasse a leitura com o dedo;

3. Apresentava-se uma escrita de confronto silábica que variava alternadamente entre a estrutura $\mathrm{CV}$ ou
$\mathrm{CC}$ para as palavras dissilábicas e $\mathrm{CCV}, \mathrm{CVC}, \mathrm{CVV}$ ou CCC para as palavras trissilábicas;

4. $\mathrm{O}$ experimentador nomeava as letras da palavra escrita pela criança e da palavra de confronto;

5. O experimentador identificava a palavra escrita de acordo com os critérios silábicos;

6. O experimentador segmentava a palavra silabicamente e quantificava o número de letras necessárias para escrever corretamente a palavra de acordo com critérios silábicos;

7. O experimentador solicitava que a criança repetisse o procedimento e quantificasse no número de letras necessárias para escrever a palavra de acordo com critérios silábicos;

8. O experimentador identificava os segmentos orais da palavra e enunciava as correspondências grafo-fonémicas, nomeando o nome ou o som da letra consoante o grupo experimental;

9. Solicitava-se que a criança repetisse os segmentos das palavras e identificasse as letras correspondentes;

10. Pedia-se à criança para repetir o procedimento e que copiasse a palavra escrita de acordo com os critérios silábicos. Paralelamente, ao tipo de instrução foram manipuladas as variáveis palavra facilitadora e tipo de orientação para a análise das palavras.

Assim, temos dois grupos experimentais: (a) Grupo experimental 1 - instrução transmissiva x palavras facilitadoras cuja sílaba inicial coincidia com o nome da letra x identificação do nome da letra; (b) Grupo experimental 2 - instrução transmissiva $\mathrm{x}$ palavras facilitadoras cuja sílaba coincidia com o som da letra $\mathrm{x}$ identificação do som da letra.

Programas de Instrução Construtivista. Os grupos experimentais 3 e 4 tiveram, ao longo do programa de intervenção, uma instrução construtivista. A instrução construtivista caracteriza-se por orientar a reflexão das 
crianças sobre o nome ou som das letras necessárias para escrever determinada palavra de acordo com os critérios silábicos. No programa de intervenção com instrução construtivista o procedimento seguido foi:

1. Era pedido à criança para escrever uma palavra da melhor forma que conseguisse, pensando nas letras e no número de letras necessárias para escrever a palavra;

2. Pedia-se à criança que lesse a palavra que tinha escrito e que acompanhasse a leitura com o dedo;

3. As crianças eram confrontadas com a escrita hipotética de um menino/a hipotético/a que tinha uma escrita conceptualmente mais evoluída, neste caso silábica;

4. O experimentador confrontava a palavra escrita pela criança com uma escrita silábica hipotética que variava alternadamente entre a estrutura $\mathrm{CV}$ ou $\mathrm{CC}$ para as palavras dissilábicas e CCV, CVC, $\mathrm{CVV}$ ou CCC para as palavras trissilábicas;

5. O Experimentador orientava a reflexão da criança para as letras utilizadas por ambas as crianças e para as correspondências com o oral;

6. O experimentador orientava a confrontação para a comparação entre as palavras escritas pelo menino e pelo menino hipotético, dando orientações específicas para que as crianças se centrassem no número de letras necessárias e em quais as letras pertinentes;

7. O experimentador solicitava que a criança enunciasse sozinha as correspondências grafo-fonémicas, orientando-a para o nome ou som da letra em função do grupo experimental. A criança deveria enunciar as que lhe pareciam corretas depois de comparar a sua escrita com a escrita hipotética de outro menino;
8. A criança escolhia uma das palavras escritas (do próprio ou do menino hipotético) e justificava porque é que considerava que estava melhor escrita, referindo quais as letras utilizadas e porque é que lhe pareciam que representavam os sons das palavras que ouvia.

Temos assim os seguintes grupos experimentais: (a) Grupo experimental 3 - instrução construtivista x palavras facilitadoras cuja sílaba inicial coincidia com o nome da letra $\mathrm{x}$ orientações para uma reflexão centrada no nome da letra; (b) Grupo experimental 4 - instrução construtivista $\mathrm{x}$ palavras facilitadoras cuja sílaba coincidia com o som da letra $\mathrm{x}$ orientações para uma reflexão centrada no som da letra.

\section{Resultados}

Para comparar a equivalência dos cinco grupos antes da intervenção, realizou-se uma ANOVA, utilizando os grupos como variável independente e a idade (em Janeiro), conhecimento do nome e do som das letras, nível de habilidade cognitiva e os resultados nas duas provas fonológicas como variáveis dependentes. O nível conceptual de todos os participantes era pré-silábico e o número de fonetizações zero, ou seja, no pré-teste, nas escritas inventadas de todas as crianças não eram mobilizadas nenhumas letras corretas. Não se verificam diferenças estatisticamente significativas em nenhuma das variáveis ( $p>0,1 \mathrm{em}$ todos os casos).

Na Tabela 2 apresentam-se os resultados obtidos pelos participantes dos diferentes grupos experimentais e pelos participantes do grupo de controlo no pós-teste quanto à evolução conceptual verificada nas suas produções escritas. Recorde-se que no pré-teste todos os escritos infantis eram pré-silábicos.

Tabela 2

Concetualizações Infantis sobre a Escrita no Pós-Teste

\begin{tabular}{ccccccc}
\hline \multirow{2}{*}{ Instrução } & Grupo & \multicolumn{4}{c}{ Conceptualizações Infantis Pós Teste } \\
\cline { 2 - 6 } & Grupo Controlo & 15 & 0 & 0 & 0 & 0 \\
\hline \multirow{2}{*}{ Instrução Transmissiva } & Grupo Exp. 1 (Nome/Nome) & 12 & 2 & 2 & 0 & 0 \\
& Grupo Exp.2 (Som/Som) & 10 & 2 & 4 & 0 & 0 \\
Instrução Construtivista & Grupo Exp. 3 (Nome/Nome) & 0 & 0 & 14 & 1 & 0 \\
& Grupo Exp. 4 (Som/Som) & 0 & 0 & 4 & 2 & 10 \\
\hline
\end{tabular}

Nota. Legenda: PS - Pré-Silábico; SSF - Silábico sem fonetização; SCF - Silábico com fonetização; SA - Silábico-Alfabético; A - Alfabético.

Verifica-se que no grupo de controlo e nos grupos experimentais 1 e 2, o número de participantes que evoluiu para escritas conceptualmente mais evoluídas é muito reduzido. No entanto, verifica-se que nos grupos experimentais $1 \mathrm{e}$
2, embora em reduzido número, alguns participantes evoluíram para níveis silábicos. Nos grupos experimentais 3 e 4 todos os participantes evoluíram para níveis conceptuais mais evoluídos (pelo menos para escritas silábicas com 
Silva, C. \& Almeida, T. (2015). Programas de Intervenção de Escritas Inventadas: Comparação de uma Abordagem Transmissiva e Construtivista.

fonetização). Verifica-se ainda que os participantes do grupo experimental 4 evoluíram na sua maioria (10 em 16) para escritas alfabéticas.

Para analisar as diferenças no número total de fonetizações (Tabela 3) entre os grupos recorremos a uma
ANOVA utilizando o grupo experimental com variável independente e o número de letras corretamente fonetizadas como variável dependente. Recorde-se que ao nível do pré-teste nenhuma das letras mobilizadas nos escritos infantis era correta.

'Tabela 3

Médias, Desvio-Padrão, Máximos e Mínimos do Número Total de Fonetizações no Pós-Teste

\begin{tabular}{ccccccc}
\hline \multirow{2}{*}{ Instrução } & Grupo & $n$ & $M$ & $D P$ & Min. & Max. \\
\hline \multirow{2}{*}{ Instrução Transmissiva } & Grupo Controlo & 15 & 6,67 & 10,16 & 0 & 37 \\
& Grupo Exp. 1 (Nome/Nome) & 16 & 14,44 & 19,82 & 0 & 61 \\
& Grupo Exp. 2 (Som/Som) & 16 & 16,38 & 21,24 & 0 & 66 \\
Instrução Construtivista & Grupo Exp. 3 (Nome/Nome) & 15 & 84,67 & 15,38 & 78 & 138 \\
& Grupo Exp. 4 (Som/Som) & 16 & 130,81 & 35,12 & 74 & 160 \\
\hline
\end{tabular}

Os resultados obtidos sugerem que as diferenças são estatisticamente significativas entre os grupos, $F(4$, $73)=96,029, p<0,01, \eta_{\mathrm{P}}^{2}=0,84$; Potência $(\pi)=1,00$. Pode ainda afirmar-se existe um efeito de dimensão elevada $\left(\eta_{\mathrm{P}}^{2}=0,84\right)$ do fator grupo experimental sobre o número total de fonetizações e que o teste utilizado é potente (Potência $[\pi]=1,00$ ) para detetar efeitos estatisticamente significativos. Especificamente, através dum teste de Pos-hoc de Tuckey verifica-se que as diferenças são estatisticamente significativas entre os grupos experimentais cuja instrução foi construtivista (3 e 4) e os restantes grupos (controlo, 1 e 2) $(p<0,01)$. Entre os grupos cuja instrução foi transmissiva e o grupo de controlo não se verificam diferenças estatisticamente significativas. Verifica-se ainda que as diferenças entre o grupo experimental 4 e 3 são igualmente significativas, ou seja, o número de fonetizações verificadas no grupo experimental 4 é significativamente superior ao verificado no grupo experimental $3(p<0,01)$.

Para analisar as diferenças no número de fonetizações de consoantes iniciais (Tabela 4) recorremos a uma ANOVA utilizando o grupo experimental com variável independente e o número de consoantes corretamente fonetizadas como variável dependente.

Tabela 4

Média, Desvio-Padrão, Máximos e Mínimos do Número de Consoantes Iniciais Corretamente Fonetizadas

\begin{tabular}{|c|c|c|c|c|c|c|}
\hline Instrução & Grupo & $n$ & $M$ & $D P$ & Min. & Max. \\
\hline & Grupo Controlo & 15 & 3,53 & 5,03 & 0 & 14 \\
\hline \multirow{2}{*}{ Instrução Transmissiva } & Grupo Exp. 1 (Nome/Nome) & 16 & 5,88 & 6,12 & 0 & 19 \\
\hline & Grupo Exp. 2 (Som/Som) & 16 & 4,19 & 5,58 & 0 & 23 \\
\hline \multirow{2}{*}{ Instrução Construtivista } & Grupo Exp. 3 (Nome/Nome) & 15 & 19,53 & 16,07 & 0 & 40 \\
\hline & Grupo Exp. 4 (Som/Som) & 16 & 33,75 & 11,57 & 0 & 40 \\
\hline
\end{tabular}

Os resultados obtidos sugerem que as diferenças são estatisticamente significativas entre os grupos, $F(4,73)$ $=28,436, p<0,01, \eta_{\mathrm{P}}^{2}=0,61$; Potência $(\pi)=1,00$. Pode afirmar-se existe um efeito de dimensão elevada $\left(\eta_{\mathrm{P}}^{2}=\right.$ 0,61 ) do fator grupo experimental sobre o número total de fonetizações e que o teste utilizado é potente (Potência [ $\pi]$ $=1,00)$ para detetar efeitos estatisticamente significativos O teste $P o s-H o c$ de Tuckey evidencia que as diferenças são estatisticamente significativas entre os grupos cuja instrução foi construtivista (G. Exp. 3 e 4) e os restantes grupos 
(controlo, 1 e $2 ; p<0,01$ ). Entre os grupos cuja instrução foi transmissiva e o grupo de controlo não se verificam diferenças estatisticamente significativas Verifica-se ainda que os participantes do grupo experimental 4 fonetizaram significativamente mais consoantes iniciais que os participantes do grupo experimental $3(p<0,01)$.

Seguindo o procedimento já enunciado anteriormente, verifica-se que existem diferenças estatisticamente signi- ficativas entre os grupos quanto ao número de vogais da primeira sílaba (Tabela 5) corretamente fonetizadas, $F(4$, $73)=28,062, p<0,01, \eta_{\mathrm{P}}^{2}=0,6$; Potência $(\pi)=1,00$. Existe um efeito de dimensão elevada $\left(\eta_{P}^{2}=0,61\right)$ do fator grupo experimental sobre o número total de fonetizações e que o teste utilizado é potente (Potência $[\pi]=1,00$ ) para detetar efeitos estatisticamente significativos.

Tabela 5

Média, Desvio-Padrão, Máximos e Mínimos do Número de Vogais da Primeira Sílaba Corretamente Fonetizadas

\begin{tabular}{ccccccc}
\hline Instrução & Grupo & $n$ & $M$ & $D P$ & Min. & Max. \\
\hline \multirow{3}{*}{ Instrução Transmissiva } & Grupo Controlo & 15 & 2,93 & 6,19 & 0 & 24 \\
& Grupo Exp. 1 (Nome/Nome) & 16 & 3,63 & 5,26 & 0 & 17 \\
& Grupo Exp. 2 (Som/Som) & 16 & 6,19 & 9,12 & 0 & 31 \\
& Grupo Exp. 3 (Nome/Nome) & 15 & 23,60 & 14,81 & 0 & 40 \\
Instrução Construtivista & Grupo Exp. 4 (Som/Som) & 16 & 33 & 12,47 & 0 & 40 \\
& & &
\end{tabular}

O teste Pos-Hoc de Tuckey evidencia que as diferenças são estatisticamente significativas entre os grupos cuja instrução foi construtivista e os restantes grupos (controlo, 1 e $2 ; p<0,01)$. Entre os grupos cuja instrução foi transmissiva e o grupo de controlo não se verificam diferenças estatisticamente significativas Ao contrário das variáveis anteriores, entre os grupos 3 e 4 não se verificam diferenças estatisticamente significativas.

\section{Discussão}

Os resultados obtidos apontam para a superioridade do impacto dos programas de treino desenhados de acordo com princípios construtivistas na evolução da qualidade das escritas inventadas, quando comparados a programas de treino desenhados de acordo com princípios transmissivos. Assim as crianças dos grupos 3 e 4 apresentam produções escritas com níveis conceptuais mais evoluídos e número de fonetizações corretas significativamente superiores às do grupos 1 e 2 , sendo que estes dois últimos grupos não diferem do grupo de controlo quando ao número letras corretamente usadas na sua escrita.

\section{1}

Pelo contrário, a metodologia transmissiva em que as letras e as respetivas correspondências com os sons são explicitamente ensinadas e exercitadas através de cópia, não se traduz numa evolução significativa, quando olhamos, quer para as hipóteses conceptuais infantis sobre a escrita, quer para o número de fonetizações totais corretas. Assim, a explicitação, a memorização, a exercitação não parecem ser suficientes para conduziram a uma restruturação das ideias infantis sobre a natureza da linguagem escrita. O papel de notação de sons não é apreendido pelas crianças e a mera enunciação das correspondências grafo-fonéticas não parece fazer sentido para elas. Resumindo, nos grupos experimentais 1 e 2 as crianças foram explicitamente ensinadas sobre a função de simbolização respetivamente, dos nomes ou dos sons das letras, no entanto, isso não foi suficiente para que abandonassem as suas conceções em que a linguagem escrita não é vista como uma forma de codificação do oral. Para além disso, o número de fonetizações corretas no pós-teste não se distingue do ponto de vista estatístico do número de fonetizações corretas produzido pelo grupo de controlo.

Dentro da abordagem construtivista, é de salientar a superioridade dos resultados obtidos pelo grupo experimental 4 (em que a sílaba inicial das palavras facilitadoras se aproximava ao som da letra e as crianças eram induzidas a pensar nos sons das letras) quando comparados aos obtidos pelo grupo experimental 3 (em que a sílaba inicial das palavras facilitadoras s coincide com o nome da letra e as crianças eram induzidas a pensar nos nomes das letras) quer no que respeita ao nível conceptual - encontramos um número elevado de crianças com escritas alfabéticas - quer no que respeita ao número de fonetizações corretas. Uma das principais dificuldades das crianças na apreensão da natureza alfabética da escrita é a compreensão de que as letras representam fonemas (unidades que são altamente abstractas), o que parece ter sido facilitado no grupo experimental 4 pelo facto das crianças serem orientadas a se focarem nos sons da letras, ao mesmo tempo que usam as letras como elemento de notação desses mesmos sons. No 
Silva, C. \& Almeida, T. (2015). Programas de Intervenção de Escritas Inventadas: Comparação de uma Abordagem Transmissiva e Construtivista.

quadro das instruções construtivistas, os resultados obtidos neste grupo parecem ir no mesmo sentido das conclusões de Caravolas, Hulme e Snowling (2001) que demonstraram a existência de relações recíprocas entre o conhecimento da correspondência letra/som e a capacidade para isolar os fonemas das palavras. Na mesma linha, também Ehri e Wilse (1985), defendem que o conhecimento das relações letras/sons ajuda os pré-leitores a estabelecer representações concretas dos fonemas das palavras. A intervenção efetuada no grupo experimental 4 parece, assim, conduzir a um pensamento concetual mais evoluído sobre a natureza da linguagem escrita, uma vez que o conhecimento sobre o som das letra é apreendido e aplicado no decurso de processos de escrita.

Numa análise complementar, confirmámos a superioridade do grupo experimental 4 na fonetização correta da consoante inicial quando comparado com o grupo experimental 3 (ainda que ambos sejam superiores aos grupos 1,2 e de controlo), embora ambos os grupos sejam equivalentes quanto à fonetização da vogal da primeira sílaba (e ambos sejam superiores aos grupos 1, 2 e de controlo). Estes resultados são consonantes com a maior frequência de escritas alfabéticas das crianças do grupo experimental 4, sugerindo ainda que as crianças do grupo experimental 3, cujas escritas são predominantemente silábicas com fonetização, recorriam sobretudo às vogais para representar os sons identificados na sílaba inicial. Esta tendência poderá ser explicada pelo facto das crianças do grupo experimental 3 terem aprendido a focar a sua atenção no nome das letras e no caso do português - muito mais do que no inglês - o som das vogais coincidir com o nome da letra (Cardoso-Martins \& Baptista, 2005; Pollo, Treiman, \& Kessler, 2008). É ainda de salientar que estas variáveis relacionadas com as características das palavras facilitadoras ou com a orientação dada às crianças na análise das palavras, não teve efeitos diferenciadores nos dois grupos experimentais que foram sujeitos a uma abordagem transmissiva.

Os resultados obtidos neste estudo revelam-se muito promissores do ponto de vista da sua aplicação pedagógica, na medida, em que identificam procedimentos facilitadores para a compreensão do valor de notação das letras por parte de crianças de idade pré-escolar. Apesar dos programas de intervenção terem sido aplicados individualmente, estes mesmos princípios poderão ser testados e aplicados em contexto de pequeno grupo, introduzindo, por exemplo, a discussão entre pares.

\section{Referências}

Alves Martins, M., \& Silva, C. (2006). The impact of invented spelling on phonemic awareness. Learning and Instruction, 16, 41-56. doi:10.1016/j.learninstruc.2005.12.005

Alves Martins, \& Silva, C. (2009). Two spelling programmes that promote the understanding of the alphabetic principle in preschool children. Journal of Writing Research, 1(3), 225-243.

Caravolas, M., Hulme, C., \& Snowling, M. G. (2001). The foundations of spelling ability: Evidence from a 3-year longitudinal study. Journal of Memory and Language, 45, 751-774. doi:10.1006/jmla.200.2785
Cardoso-Martins, C., \& Batista, A. (2005). O conhecimento do nome das letras e o desenvolvimento da escrita: Evidência de crianças falantes do português. Psicologia: Reflexão e Critica, 18, 330-336. doi:10.1590/S0102-79722005000300006

Clark, R. E. (2009). How much and what type of guidance is optimal for learning from instruction. Constructivist Theory Applied to Instruction: Success or Failure, 158-183.

Ehri, L. (1998). Grapheme-phoneme knowledge is essential to learning to read words in English. In J. L. Metsala \& L. C. Ehri (Eds.), Word recognition in beginning literacy (pp. 3-40). London: Lawrence Erlbaum.

Ehri, L. C., \& Wilce, L. S. (1985). Movement into reading: Is the first stage of printed word learning visual or phonetic? Reading Research Quarterly, 20, 163-179. doi:10.1111/14679280.00164

Ferreiro, E. (1988). L'écriture avant la la lettre. In H. Sinclair (Ed.), La prodution des notations chez le jeune enfant (pp. 18-69). Paris: Presses Universitaires de France.

Ferreiro, E. (2002). Escritura y oralidad: unidades, niveles de análisis y consciencia metalinguistica. In E. Ferreiro (Ed.), Relaciones de (in)dependencia entr oralidad y escritura (pp. 151-171). Barcelona, España: Geddisa.

Ferreiro, E., \& Teberosky, A. (1986). Psicogênese da linguagem escrita. Porto Alegre, RS: Artes Médicas.

Kirschner, P. A., Sweller, J., \& Clark, R. E. (2006). Why minimal guidance during instruction does not work: An analysis of the failure of constructivist, discovery, problem-based, experiential, and inquiry-based teaching. Educational Psychologist, 41(2), 75-86. doi:10.1207/s15326985ep4102_1

Kuhn, D. (2005). Education for thinking. Cambridge, MA: Harvard University Press.

Kuhn, D. (2007). Is direct instruction an answer to the right question? Educational Psychologist, 42(2), 109-113. doi:10.1080/00461520701263376

Levin, I., Shatil-Carmon, S., \& Asif-Rave, O. (2006). Learning of letter names and sounds and their contribution to word recognition. Journal of Child Psychology, 93, 139-165. doi:10.1016/j.jecp.2005.08.002

Ouellette, G., \& Sénéchal, M. (2008). A window into early Literacy: Exploring the cognitive and linguistic underpinnings of invented spelling. Scientific Studies of Reading, 12, 195-219. doi:10.1080/10888430801917324

Pollo, T. C., Treiman, R., \& Kessler, B. (2008). Three perspectives on spelling development. In E. J. Grigorenko \& A. Naples (Eds.), Single-word reading: Cognitive, behavioral, and biological perspectives (pp. 175-189). Mahwah, NJ: Erlbaum.

Raven, J., Court, J. H., \& Raven, J. C. (2001). Manual Raven Matrices Progressivas (3. ed.). Madrid, España: TEA.

Schmidt, H. G., Loyens, S. M., van Gog, T., \& Paas, F. (2006). Problem-based learning is compatible with human cognitive architecture: Commentary on Kirschner, Sweller, and Clark (2006). Educational Psychologist, 42(2), 91-97. doi:10.1080/00461520701263350

Silva, A. C. (2003). Até à descoberta do principio alfabético. Lisboa, Portugal: Fundação Calouste Gulbenkian.

Silva, C., Almeida, T., \& Alves Martins, M. (2010). The letter's names and the letter's sound: It's implication for the phonetization process. Readind and Writing, 23(2), 147-172. doi:10.1007/s11145-008-9157-3

Silva, C., \& Alves Martins, M. (2002). Phonological skills and writing of pre-syllabic children. Reading Research Quarterly, 37, 466-483. doi:10.1598/RRQ.37.4.6 
Sweller, J. (2010). Cognitive load theory: Recent theoretical advances. In J. Plass, R. Moreno, \& R. Brunken (Eds.), Cognitive load theory (pp. 29-47). New York: Cambridge University Press. doi:10.1017/CBO9780511844744.004

Sweller, J. (2012). Human cognitive architecture: Why some instructional procedures work and others do not. In K. Harris, S. Graham, \& T. Urdan (Eds.), APA educational psychology handbook: Theories, constructs, and critical issues (Vol. 1, pp. 295-325). Washington, DC: American Psychological Association. doi:10.1037/13273-011

Sweller, J., Kirschner, P. A., \& Clark, R. E. (2007). Why minimally guided teaching techniques do not work: A reply to commentaries. Educational Psychology, 42(2), 115-121. doi:10.1080/00461520701263426

Treiman, R. (1994). Use of consonant letters names in beginning spelling. Developmental Psychology, 30(4), 567-580. doi:10.1037/0012-1649.30.4.567

Treiman, R. (2006). Knowledge about letters as a foundation for reading and spelling. In R. M. Joshi \& P. G. Aaron (Eds.), Handbook of orthography and literacy (pp. 581-599). Mahwah, NJ: Erlbaum. 